\title{
9. Evolutionary Change: Nothing stands still in biology
}

\author{
Lindell Bromham
}

The world around us is the product of evolution - not just the actual biological organisms such as the trees, birds and insects, but also many features of the environment such as the soil, atmosphere and buildings, which have been constructed by the actions of organisms over time. This life-built environment is in a constant state of change, as are all the biological lineages that inhabit it. So if you want to understand the world around you, then a passing familiarity with the nuts and bolts of evolutionary change is an important part of your intellectual toolkit.

Understanding the processes of evolutionary change is also essential to grasping biological phenomena that affect our everyday lives, such as recognising the way that your antibiotic prescription contributes to the incidence of untreatable infections, or judging whether genetically modified food is dangerous. While most people in our society recognise that the species alive on earth today are descended from earlier types, common notions of evolutionary change such as 'the survival of the fittest' can just as often mislead as enlighten. Evolution is at the same time breathtakingly simple in mechanism, and devilishly complex in outcome.

In this chapter, I briefly summarise the basics of evolutionary change: how genomes change, species evolve, and biodiversity is shaped over time. The point I wish to emphasise is that evolutionary change is continuous and inevitablenothing stands still in the biological world. Because DNA replication is almost but not entirely perfect, mutations arise in each generation. Some of these mutations rise in frequency until they become permanent changes to the genetic material that characterises a population. Over generations, in every population, genetic change accumulates, driving a process of divergence that ultimately results in the formation of new species. As new species arise, others are lost to extinction, so the composition of the biosphere is in constant flux. The changing nature of species and communities shapes the environment, creating a constantly shifting biological landscape that all species must adapt to. Our own species has had to adapt to changing conditions, even as it has dramatically changed the environment of nearly all other species in the biosphere. 
I also want to highlight the way ideas change over time, using a few key debates to demonstrate that evolutionary biology itself is in a constant state of flux, as new ideas prompt the search for new data or novel analyses, and these new data and analyses generate further new ideas. One of the main themes that has threaded through many debates in evolutionary biology since its inception is whether evolution is primarily driven by small changes accumulating slowly and gradually over long periods of time, or rapidly in occasional bursts of large changes. Although the nature of the data has changed dramatically, now that we have access to whole genome sequences of an increasing number of species, many of the core ideas have parallels to debates that have waged since Darwin's revolutionary publication On the origin of species (1859).

The best place to start if you want to understand evolutionary change is to consider the raw material of evolutionary change: a mutation occurring in an individual's DNA.

\section{We are all mutants}

Life depends on DNA copying. Whenever a cell gives rise to a new cell, its genome, consisting of all the DNA that is inherited as a coherent unit, must be copied in its entirety (Figure 1). Because the integrity of genetic information is critical to survival, the genome is copied with astounding accuracy, with only a few mistakes made for every hundred million nucleotides ('letters') of DNA copied. But because genomes of most complex creatures are so big (in the case of humans, roughly 3 billion nucleotides of DNA), and are copied dozens of times in a typical generation from parent to offspring, even this vanishingly small error rate results in new mutations with every generation. Similarly, damage to DNA, such as that caused by mutagenic chemicals or ultraviolet light, is usually perfectly repaired by a barrage of specialised cellular equipment, but the occasional missed or misrepaired damage slips through the net, permanently changing the DNA sequence. The upshot is that each new individual might have 100 or more entirely new mutations that neither of the parents carried (Nachman and Crowell 2000).

Mutations, whether created by mistakes in copying or unrepaired damage, are accidents. They are not deliberate changes, and they occur with no regard for consequences. Mutations that change DNA sequences that encode the instructions for growth, survival and reproduction will tend to be harmful. This is because a random change to organised information almost never results in improvement (you can test this next time you write an email by randomly replacing words with alternatives chosen by a blind draw from the dictionary). Very, very rarely will a random change to the useful information in the genome make that individual function better, thus imparting a greater chance of successful reproduction and 
representation in coming generations. However, some mutations may be neither harmful nor beneficial. A mutation that occurs in a part of the genome that does not contain important instructions for making or maintaining the organism may make no difference to its carrier's chances of survival and reproduction. Even some mutations that occur in essential genes may have little impact on the organism's success, for example if the DNA or protein sequence is altered but it still functions as normal. These 'neutral' mutations can be carried by an individual without cost or benefit.

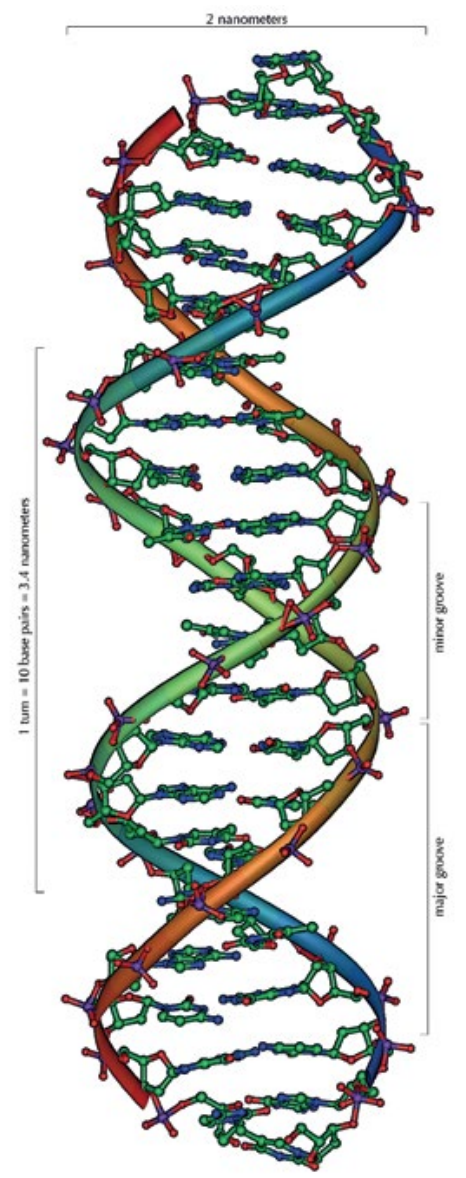

\section{Figure 1 The most beautiful molecule in the world: A short section of a DNA double-helix.}

DNA is the heart of the living world, beautiful not only in form but also in function. The DNA molecule is made of two intertwined strands made of linked phosphate and sugar (ribose) molecules, with four kinds of nitrogenous bases (A, C, T and G) making the steps of the spiral staircase. The bases pair between the strand, each base matched to its complement-A pairs with $\mathrm{T}$, and $\mathrm{G}$ pairs with $\mathrm{C}$. This means that one strand of DNA can act as a template to create a new strand containing the matching base sequence, and that new strand can act as a template to create a sequence identical to the original strand. In this way, the genetic information can be faithfully copied from cell to cell, from generation to generation.

Source: Figure created by Michael Ströck, available through WikiCommons at commons.wikimedia.org/ wiki/File:DNA_double_helix_horizontal.png. 
How can accidental changes to the information in the genome be the basis of the evolution of complex and well-adapted life? Random mutations may be the raw material of evolution, but they are sorted by natural selection.

If a mutation harms its carrier's chances of surviving and reproducing, then, by definition, that mutation is less likely to end up in a healthy offspring in the next generation. So harmful mutations will either fail to make it into the next generation at all (if they result in death or sterility) or will diminish in numbers with each generation (if they reduce the chance of survival and reproduction). This filtering out of harmful mutations is referred to as 'negative selection' and it is the only process that prevents evolutionary change at the genomic level. If there is a sequence in the genome that is very similar, or identical, in many different and otherwise divergent species, then that sequence must be so important that changing it almost always results in negative consequences. For example, there is a protein sequence in the active site of the enzyme DNA polymerase (an essential part of the cellular equipment that copies DNA: Figure 2) that is so similar in bacteria, animals, plants and fungi that we can infer that, for billions of years, almost any mutation that ever occurred in this particular DNA sequence was removed from the population by negative selection (Bromham 2000, Patel and Loeb 2000).

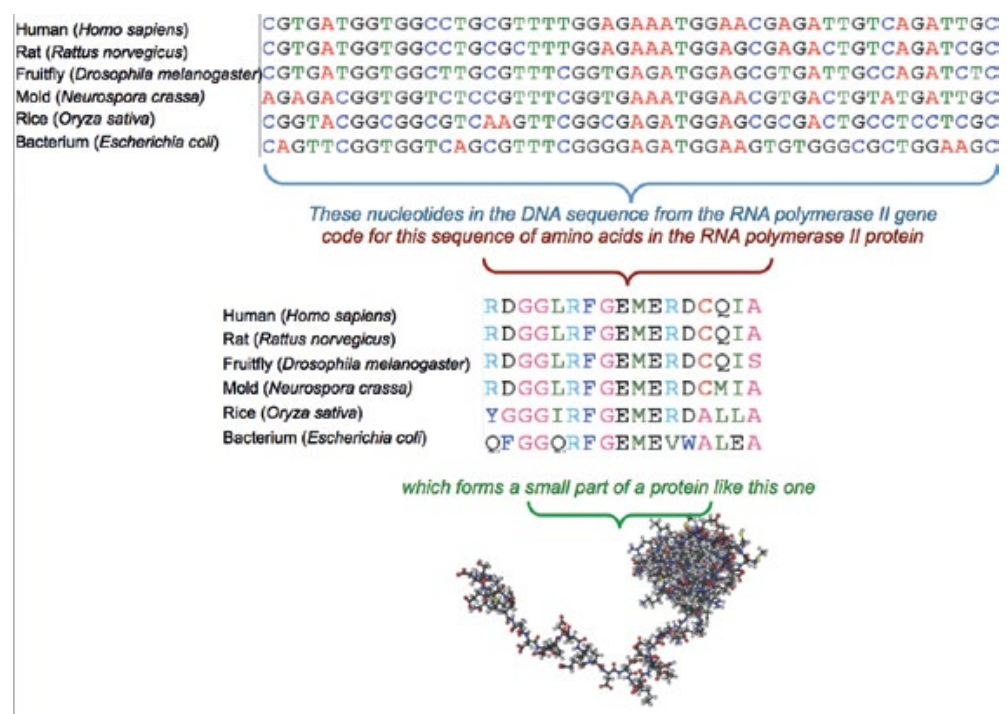

Figure 2 Family resemblance: Selection maintains important DNA sequences against change.

The information needed to build an organism is coded in the genome in the four bases of DNA (represented by the letters A, C, G and T). In this example, the DNA sequence is part of the RNA polymerase II gene that makes an essential part of the cellular machinery. Each three bases are translated into one amino acid. Amino acids are the subunits of proteins represented by 20 different letters (for example, the conserved motif RFGEME can be translated as the amino acid sequence arginine-phenylalanine-glycine-glutaminemethionine-glutamine). Each of these amino acids forms one tiny piece of a peptide chain which will fold into a specific three-dimensional structure and join with other proteins to form a working enzyme. 
Very occasionally, a random change in the genome sequence will somehow increase the individual's chance of surviving and reproducing. For example, a chance mutation in a blood protein gene that makes it more efficient at taking up oxygen at low barometric pressure might increase the chances of survival of an individual living at high altitude, who will then be more likely to leave descendants who also carry copies of that mutation (Bigham et al. 2010). By definition, any change that increases the chances of successful reproduction will have a tendency to end up in more members of the next generation, and therefore will tend to increase with each passing generation (as long as it remains at a relative advantage). This is positive selection, the process that people associate with the phrase 'survival of the fittest'.

Beneficial mutations will tend to increase in frequency until they replace all alternative versions in the population, and harmful mutations will tend to decrease in frequency until they disappear from the population. But what about mutations that have little or no effect on the chances of successful reproduction, for example a change in a part of the genome that does not code for anything important, or change to the DNA sequence of a gene that does not alter the function of the gene product? These 'neutral' mutations will not increase their chances of appearing in the next generation, but neither will they harm their carrier's chance of reproduction. So whether or not they are passed on down the generations depends entirely on chance. Many will disappear when their carriers fail to reproduce, but others will, by chance, increase in frequency if their carriers happen to have many descendants. And occasionally, by sheer luck, some of the neutral variants will just happen to increase in frequency until they replace the other variants in the population. So not all evolution at the genetic level is due to natural selection - some of it is the result of the random sampling of alternative DNA sequences that occurs every generation. For example, it has been estimated that there are around 35 million differences in the DNA sequences between the chimpanzee and human genomes, but a substantial proportion of these mutations will have no impact on the ability to build, maintain and operate an ape (Varki and Altheide 2005). The silent differences between the genomes of humans and chimps cannot have been influenced by selection, so they must have evolved by drift (random sampling of functionally equivalent sequences).

So the first two fundamental processes of evolution are mutation - whereby heritable change is generated - and substitution - whereby a mutation rises in frequency over many generations until it replaces all alternative traits in the population. This process may seem very obvious, but it is worth keeping these basic mechanisms in mind in order to appreciate the inevitability of evolutionary change. First, mutations constantly arise irrespective of their usefulness or harm. Mutations are accidents, most of which are bad, some of which do no harm, 
and very few of which are improvements. Second, if a mutation is to become a fixed part of a species makeup it must go through the process of substitution. Any characteristic shared by an entire sexually reproducing species must have started in a single individual (or several, due to recurrent mutation) then increased in frequency until it replaced all alternatives. Third, the role of chance in the process of substitution is often underestimated. Random mutation and chance substitution, even in the absence of natural selection, can give rise to evolutionary diversity and complexity. To understand why, we should consider a third fundamental process in evolution: divergence.

\section{The inevitability of change}

From a genomic point of view, evolutionary change is inevitable; mutations constantly arise, and though many will be removed by natural selection, others will become a fixed part of the genome, through chance or selection. Even species that appear not to change over time are in constant flux at the molecular level. Species referred to as 'living fossils', such as the coelacanth, may remain virtually unchanged to the eye for tens of millions of years, but their genomes have continued to steadily accumulate change (Lampert et al. 2012). The only thing that can halt evolutionary change is negative selection (removal of harmful mutations).

The continuous action of mutation and substitution results in divergence. If populations are divided by any means then any changes that accumulate in one population are not shared with other populations, and so the populations become progressively more different over time as they acquire more and more unique changes. When two populations are so different that individuals from one population will not interbreed with another, we tend to call them separate species. So anything that divides populations and stops them sharing any new mutations will kickstart the process of divergence that may ultimately lead to the formation of new species. However, there has been a lot of debate about which mechanisms are the main drivers of speciation.

Darwin focused on what is now often referred to as ecological speciation, when natural selection drives populations to become adapted to different conditions (Darwin 1859). Under this view of evolutionary divergence, sections of a widespread population gradually accumulate adaptations that better equip them to survive and breed in their own particular circumstances. At first we might recognise these as variants within the same population, then as they became more distinct we might regard them as local races. As more differences accumulate between the populations, they may be referred to as subspecies. Eventually they become so distinct that we could happily recognise two separate 
species, which may be so divergent that they rarely, if ever, interbreed in nature. According to this Darwinian view of speciation, the distinction between local varieties, subspecies and species may be blurred as populations gradually accumulate more and more differences.

But what prevents the mutations that arise in one section of the population from flowing through to all other parts, eroding the differences between local races? In the mid-twentieth century the focus of speciation research shifted toward the nature of the barriers that divided populations, preventing gene flow and thus allowing the build-up of unique genetic changes in subpopulations (Mallet 2010). Geographic barriers are the most obvious example, as when a mountain range or river prevents individuals from meeting and mating. But barriers to interbreeding might come about through behaviour, for example through changes to mating rituals, or temporal separation, such as different flowering times. Once barriers to interbreeding arise, by whatever means, any mutations that occur in one population cannot move into the other population. Each population therefore accumulates a different set of mutations, which go on to create unique patterns of substitutions, fuelling continual divergence. Selection might then favour the evolution of mate recognition that prevents individuals wasting time mating with members of different populations, reinforcing the lack of gene flow and further enhancing their divergence.

In recent decades, advances in technology have allowed an intense focus on the genetic basis of speciation (Wolf et al. 2010). Some scientists look for specific genes involved in particular speciation events (Nosil and Schluter 2011). For example, a number of 'speciation' genes have been identified, such as Odysseus ( $\mathrm{OdsH}$ ) in fruit flies and $\operatorname{Prdm} 9$ in mice, that seem to disrupt normal chromosome pairing in hybrids (Bhattacharyya et al. 2013). These genes prevent gene flow by making it impossible for individuals produced by cross-species mating to have their own offspring (Orr et al. 2004). Other scientists take in the broader picture, investigating genome-wide processes that contribute to the divergence between populations. For example, speciation can occur when one lineage undergoes a complete doubling of the genome: the differences in chromosome numbers between populations can create a barrier to the formation of viable hybrids, preventing further interbreeding (Rieseberg and Willis 2007)

But even small genetic changes can contribute to the formation of a new species. For a mutation to become fixed in a population, it must be able to work with the other traits present in the population. This is because any particular mutation can only be passed on to the next generation if the individual that carries it survives and breeds. In a sexually reproducing population, each new individual born has a selection of the different variants for each gene that are currently in that population's gene pool. Any individual with a set of gene variants that do not work well together will have a reduced probability of reproducing, and 
so those particular variants will have less chance of making it into a successful offspring in the next generation. In each generation, any mutation is tested against different sets of genetic variants sampled from the population. It can rise in frequency if, on average, individuals carrying that mutation do relatively better than others in the population. So for a mutation to become fixed in a population it must generally work well with the other genetic variants that it may find itself sharing an individual body with.

But the mutations present in one population have not been tested for harmonious operation with the variants present in other populations, and this means that the particular genetic variants in one population may be incompatible with those found in its sister population. So when individuals from two populations mate and produce a hybrid, their offspring might inherit substitutions from one population that do not work well with the changes accumulated in the other population, resulting in unfit hybrids with disharmonious genomes. The more genetic differences between the populations, the greater the chance that a combination of genes from the two populations will contain unviable combinations of mutations (Welch 2004).

Finally, it is important to note that, while the focus of the preceding discussion was on the divergence that pushes populations apart, separated populations occasionally come back together again. In some cases, this might be through 'de-speciation', where the ecological differences between species niches collapse (McKinnon and Taylor 2012). In other cases, long-diverged lineages can form viable hybrids that give rise to new species (Abbott et al. 2013). In fact, the analysis of whole genomes of an increasingly wide range of species has revealed that the barriers to gene exchange between lineages are sometimes more permeable than had been supposed. Genes can move between distantly related lineages, a phenomenon referred to as horizontal gene transfer (to distinguish it from the vertical transfer of genes from parent to offspring). For example, bacterial species can exchange genes for drug resistance (Ochman et al. 2000). Parasite genes have made their way into hosts and host genes into parasite genomes (Mower et al. 2004). It has even been suggested that seaweed consumption has promoted the transfer of genes from marine bacteria to the gut bacteria of people in Japan, so now the gut bacteria can manufacture enzymes that can digest the polysaccharides found in nori (which is made from the red alga Porphyra: Hehemen et al. 2010). The result is genomes that are a patchwork of genes with different histories: for example, a gene that plays a key role in the formation of the human placenta is derived from a virus (Mi et al. 2000). So while evolution is commonly displayed as a tree, with branches splitting again and again to form a large number of separate twigs, sometimes evolutionary history might be better thought of as a net, with strands both dividing and intertwining. 


\section{Generation of biodiversity}

The inevitability of evolutionary change - mutations will always arise, some will become a fixed part of the gene pool, so populations will always divergemeans that new species are constantly arising. But species are also continually lost to extinction. Species extinction - the death of all members of a species so that their unique genetic heritage is irreversibly lost - is as normal a part of evolution as the generation of new species.

Extinction is a familiar concept to us. We are constantly reminded of lost forms, from dodos to dinosaurs, and concerned by the prospect of imminent extinction of species under threat, such as polar bears, orange-bellied parrots, or the Lord Howe Island stick insect. But the fact of extinction is a relatively recent discovery. Fossils must have been unearthed throughout human history, but if you do not know that the biological world has a long hidden history, it might not be obvious that fossils are the remains of extinct species (Rudwick 1976). For example, it has been suggested that the remains of ice age beasts in Europe could have been interpreted as the bones of heroes of legend, and that ceratopsid dinosaur bones exposed in the Gobi desert may be the source of tales of gryphons (Mayor 2000). When dinosaur skeletons found in England were identified as the remains of giant reptiles, no longer to be seen alive, it proved beyond doubt that the biological world had changed dramatically over time.

If species are forever gained and lost, does the biosphere steadily accumulate species, or does it maintain a steady state, with new species replacing old species in the economy of nature? You would think that this would be a simple question to answer, simply by counting the number of species over time. But new data and new analyses provide continual fuel to an ongoing debate.

One of the key pieces of evidence has been numerical analyses of taxonomic diversity from the fossil record, plotting the total number of recognised species over time (or, more commonly, higher taxonomic groups of related species such as genera and families). Figure 3 shows a typical example. Two patterns stand out on this graph. First, the number of recorded genera has a clear increase over time, with the highest diversity towards the present day (on the right hand side of the graph). Second, the increase in diversity has not been constant over time; there are occasional catastrophic losses of diversity identified as mass extinction events, which tend to be followed by rapid increases (Jablonski and Chaloner 1994). 


\section{Biodiversity during the Phanerozoic}

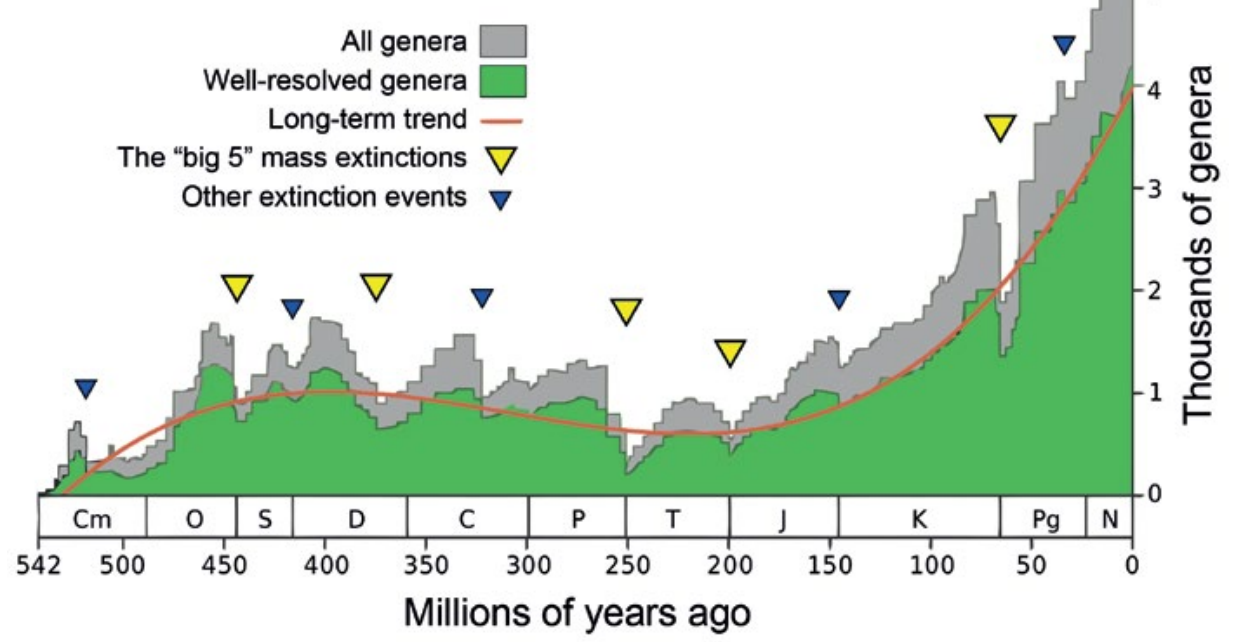

Figure 3 Biodiversity over evolutionary time, estimated from the fossil record of marine animals from the beginning of the Phanerozoic (542 million years ago) to the present day.

While this count of the number of identified genera (groups of related species) per time period seems to show a clear increase toward the present, there are a number of biases that could produce this trend. Although there are a number of extinction events identified on this graph, these are also a matter of debate. A mass extinction is recognised as a period when a higher than usual number of species make their last appearance in the fossil record, but this will be affected not only by biological or geological events, but also by the resolution of the fossil record, and by dips in the amount of sedimentary rock available for palaeontological sampling (Peters and Foote 2001, Smith 2001).

Source: Figure created by Albert Mestre, based on the analysis of Rohde and Muller (2005), available through WikiCommons at commons.wikimedia.org/wiki/File:Phanerozoic_Biodiversity.svg.

But this figure highlights the complicated nature of scientific research and discussion. Rarely can data be taken at face value; all patterns must be interpreted in light of potential biases in data collection and analysis. There are many reasons why the number of species (or other taxonomic groups) recorded for each geological time period might not be an unbiased estimate of how many species actually existed at any point in time. For example, if more scientific effort is directed at a particular period, then we would expect more species to have been described from that period, just as we would expect a higher species count from a well-studied rainforest than one that had rarely been sampled. So not surprisingly, periods that have been more intensively studied may have higher recorded biodiversity (Lloyd et al. 2012, Sheehan 1977). The amount of available fossil-bearing rocks will also influence the number of fossil species that have been discovered (Smith 2001). Instead of resulting from an increase in biodiversity over time, the upswing in species towards the present may reflect the 'Pull of the Recent': we are more likely to have data on recent taxa than those from the distant past. So we cannot take the uncorrected counts of described 
species over time as evidence for increase in biodiversity, without correcting for ascertainment bias. However, different statistical corrections lead to different conclusions, so at this point in time, we cannot be sure of the answer to the apparently simple question of whether or not biodiversity has increased over time (Peters and Foote 2001).

Figure 3 points to another very important pattern read from the fossil record: the boom and bust pattern of biodiversity over time. Extinction is a constant feature of evolution, but a number of mass extinction events are recognised where the number of taxa that make their last appearance is higher than expected. These dips in the diversity curve have been interpreted as evidence for occasional periods of upheaval when a global catastrophe, such as a massive meteor strike, prolonged period of volcanism, or rapidly changing climate results in above-average species losses.

But, as with so many ideas in evolutionary biology, there is vigorous debate concerning the meaning of the dips and peaks in the diversity curve. Some analyses identify as many as 18 mass extinction events, others find only a few outliers from the background extinction rate, while some consider that all extinction events form a continuum of magnitude from which no particular events stand out (Bambach 2006, Jablonski and Chaloner 1994). Furthermore, some of the dips in the diversity curve may be due to slow rates of origination of new lineages, rather than raised extinction rates (Bambach et al. 2004). It has even been suggested that the diversity curve is, for the most part, indistinguishable from a random walk in extinction and origination rates (Cornette and Lieberman 2004). So a consideration of global diversity patterns over time illustrates the important point that rarely in evolutionary biology can we simply read past patterns and processes straight from the raw data. All hypotheses require testing that takes into account the unavoidable biases inherent in all observations.

\section{Steps or leaps?}

There is, and has always been, controversy about the nature of evolutionary change. Just as discussions about the process of speciation have changed over time, these debates over the tempo (pace) and mode (mechanism) of evolutionary change illuminate how evolutionary biology is shaped over time as new evidence is uncovered, and new ideas discussed.

One of the earliest debates was on the nature of the mutations that drive the formation of new species. Darwin argued strongly for gradual divergence, with populations steadily acquiring nearly insensible changes, until the summed differences were great enough to form distinct gaps between species. Darwin used the phrase 'Natura non facit saltum' - nature does not leap (Darwin and 
Wallace 1858). But not all of his contemporaries were convinced that the myriad of tiny variants found naturally in all populations could ever be sufficient to explain the distinct gaps between recognised species. Instead, some considered that the differences they observed between species were of a different kind from the variations typically found in populations. Scientists in the mutationist school felt that the 'unbridgeable gaps' between species, families and orders could only be created by leaps in form, arising from rare macromutations (genetic changes of large effect). Discussion of the mutationist model of evolution in the mid-twentieth century focused on the concept of the 'hopeful monster', a hypothetical individual born with a macromutation that makes it so strikingly different from other members of its species that it gives rise to a new distinct lineage. Under this hypothesis, the differences between species are not simply a sum of the tiny variations that occur every generation: new species arise by leaps and bounds rather than by very many small steps.

The mutationist school of thought was displaced by the rebirth of Darwinian evolutionary theory in the mathematical framework of population genetics. These mathematical models showed how, despite the intuitive implausibility, it was indeed possible for natural selection to drive significant changes between populations simply through the accumulation of tiny changes, each one of small effect, over very many generations. Furthermore, the mathematical models suggested that macromutations were less likely to contribute to the formation of evolutionary novelty, because a single, large change has a high probability of reducing fitness, so is unlikely to survive and breed.

But ideas similar to the mutationist view continue to be debated, for example in the new field of 'evo-devo' (evolutionary development). Many scientists working in this field have discussed the evolutionary potential of mutations in developmental genes which cause dramatic changes in body plan, for example changing the number or type of wings and other appendages (Marshall et al. 1999). It has been suggested that notable differences between distinct kinds of animals might be attained through relatively few mutations of large effect, rather than by the gradual accumulation of tiny differences (Gellon and McGinnis 1998). But while these mutations have been instrumental in understanding development (the process whereby the information in the genome is used to build and operate an individual's body), their role in evolution of the major different kinds of animals is less clear (Bromham 2011, Hoekstra and Coyne 2007). The question is not whether such developmental macromutations can arise in populations, but whether they can give rise to new kinds of species when they do. For a hopeful monster to survive, the new trait must be sufficiently well integrated not simply to permit survival, but to give 
an advantage over other forms in the population that would allow it to compete and thrive (Maynard Smith 1958). For example, an extra set of wings is not much good if your neural circuitry is not wired up to allow you to fly with them.

\section{Tempo and mode}

The tension between gradualism (moving forward by many tiny steps) and saltationism (leaping forward by few large jumps) pervades many aspects of evolutionary biology. As with most aspects of biology, there are examples of both and it is often impossible to draw a clean line between the two extremes. For example, a new plant variety may arise in a single generation by hybridisation, or it may arise over many generations by a series of successive tweaks to existing traits (Soltis and Soltis 2009). A bacterial strain may acquire antibiotic resistance by gradual steps, through natural selection on mutations to its existing genes (Normark and Normark 2002), or it may become resistant in a single leap when it acquires a gene from another strain (Ochman et al. 2000). There has been an ongoing debate about the relative contributions of cumulative tiny steps and large single leaps to the generation of biodiversity.

This debate for and against Darwinian gradualism crystallised around discussion of the punctuated equilibrium hypothesis (Maynard Smith 1981). This hypothesis has been interpreted in many ways, but the essence is that most of the major changes that generate biological diversity occur not through the continuous collection of small variants but in rapid bursts of change associated with speciation events. Evidence for 'punc eq' (pronounced 'punk-eek') came largely from the fossil record, where some species were reported to persist for millions of years with little change, then to be rapidly replaced by a new, related species (Stanley 1979). This pattern was interpreted as a signal that speciation primarily occurred when a small subpopulation became isolated from a larger established population, and it was often implied that the genetic change underlying the rapid change was not driven by the gradual action of natural selection (Gould 1980).

But, as with everything in evolutionary biology, there is always more than one way to interpret observations. Punctuated equilibrium was promoted as a refutation of Darwinian orthodoxy (Gould 1980, 1997), but no one, including Darwin, ever expected that the pace of morphological evolutionary change would be uniform over time. The gradual model refers to the expectation that most evolutionary change is built from the accumulation of small changes over generations, which does not rule out acceleration in the rate of change when the environment changes rapidly. Bursts of change can also correspond to the influx 
of new genetic variants by mutation or migration (Elena et al. 1996). Negative selection can hold traits in stasis by removing variants that arise by mutation (Coyne and Charlesworth 1997).

In the often vituperative debate between the two schools of thought, punc eq was labelled 'evolution by jerks', and Darwinian gradualism was called 'evolution by creeps'. One of the underlying causes of the animosity was a cultural difference: punctuated equilibrium was proposed, and largely championed, by palaeontologists who study large-scale changes in biodiversity over time as recorded in the fossil record (Sepkoski 2012). Many of the critics were 'neontologists' (biologists who work on living species), particularly those who focused on the population genetic basis of evolution. Perhaps as a consequence of these differing viewpoints, it has been sometimes unclear whether the debate is about pattern or process. Gradual cumulative change in a population over hundreds of thousands of generations may appear instantaneous in the fossil record (Maynard Smith 1983), and observable population genetic change can occur in bursts (Coyne and Charlesworth 1996). So it is difficult to assess whether rapidity of change in the fossil record rejects the Darwinian model of evolution, unless we have a clear idea of how fast is too rapid to fit the gradualist model of many tiny steps.

\section{Molecular clocks}

The punctuated equilibrium debate has now moved to the realm of the genome. When the genetic revolution made it possible to compare biomolecular sequences from different species, a surprising pattern began to emerge. When the amount of divergence between sequences was plotted against evolutionary time, a strikingly linear relationship emerged: the longer two species had been evolving separately, the more differences you would observe between their genomes (Bromham and Penny 2003). This was surprising, as it had been expected that molecular evolution would track adaptation, changing at different rates in different lineages or evolutionary periods.

A whole new body of theoretical work arose to explain the observation of an apparently steady accumulation of genetic changes over time. If most changes at the molecular level had no significant effect on an organism's chances of survival and reproduction, then those mutations would not be removed by negative selection nor promoted by positive selection, so would simply accumulate at a rate determined by the mutation rate. Whatever the cause, the apparently clock-like evolution of molecules over time promised a new way of estimating the time scale for evolution: simply comparing gene sequences from different species could tell you how long it was since they had last shared a 
common ancestor. One of the first molecular clock estimates prompted a radical revision of our own place in the evolutionary tree, showing that humans and chimpanzees shared a common ancestor only a few million years ago, in contrast to the commonly held belief that they were separated by tens of millions of years of evolution (Sarich and Wilson 1967).

The molecular clock hypothesis has matured since then and, like so many things in evolutionary biology, turns out to be a lot more complicated than might have been hoped. Not surprisingly, the rate of molecular evolution varies dramatically across the genome: important sequences change slowly because most mutations are removed by negative selection, large parts of the genome change more readily because mutations in them do not seem to affect survival and reproduction, and some parts of the genome are under positive selection that promotes a faster rate of change. More intriguingly, the rate of molecular evolution also varies between lineages: for example, a typical gene in a mouse evolves roughly three times faster than the equivalent gene in a human. Some progress has been made in untangling the causes of variation in the rate at which genomes evolve (Bromham 2009). Since most mutations in the genome arise from copy errors, genomes that are copied more often accumulate changes more rapidly, so it is not surprising that mice, which can have 50 generations in the time it takes for a human baby to grow up and reproduce, would accumulate more genetic changes. The copy error effect might also explain why rate of molecular evolution is related to plant height (because shorter plants undergo more cell divisions per year: Lanfear et al. 2013), why social insects have faster rates of molecular evolution (because queens can lay thousands of eggs: Bromham and Leys 2005), and why most new mutations in the human genome originate in fathers (because it takes more cell generations to make sperm than eggs: Li et al. 2002).

But there are other differences in molecular rate between lineages that are harder to explain. One is the emerging evidence that biodiverse lineagesthose that have produced more living species than their relatives - have higher rates of molecular evolution (Barraclough and Savolainen 2001, Lanfear et al. 2010). This observation has given rise to the claim that the genome evolves in a punctuated manner, with most substitutions occurring in bursts associated with speciation events (Pagel et al. 2006). However, an alternative model is more akin to the Darwinian gradualist view. We have already seen that the accumulation of mutations in separated populations results in the accretion of hybrid incompatibilities: sequence variants that work well in the context of one population, but when mixed across population boundaries produce disharmonious hybrids. Rates of mutation are influenced by all manner of species traits, such as body size, generation time, fecundity, longevity and mating system (Bromham 2009). If mutations drive substitutions, and if 
substitutions drive hybrid incompatibility, then might we not expect lineages with greater mutation rates to more rapidly form new species? Evidence points to a relationship between mutation rates and rates of diversification in at least some cases (Duchene and Bromham 2013, Lanfear et al. 2010).

The link between species diversity and molecular evolution is now well established, but distinguishing the direction of causation is not simple. At this stage, we cannot say for sure whether the process of diversification speeds the rate of genome divergence, or whether the rate of accumulation of changes in the genome is a driver of the evolution of biodiversity. So in the post-genomic era, the debates that have been threaded through the whole history of evolutionary biology - many slight variations versus few key macromutations, gradualism vs punctuation - have been carried through to a consideration of the patterns of changes in DNA sequences.

\section{Keeping up with a changing world}

No species exists in isolation; all must persist in the face of constant change if they are to avoid extinction. The environment of a species is partly determined by the abiotic conditions (such as the minimum temperature, average rainfall, or available nutrients), and partly by other species, either directly (e.g. predation, herbivory, parasitism, competition) or indirectly (e.g. decomposition, nutrient cycling, reef-building). Species both create and respond to changing environments, creating a tangled web of interactions in space and time.

Changes in global climate may explain some of the broadscale patterns in biodiversity over time (Ezard et al. 2011, Mayhew et al. 2012). Climate change, in space or time, can drive the formation of new species by favouring individuals better able to survive and thrive under the new conditions, resulting in directional trends in species traits such as temperature tolerance (Hua and Wiens 2013). As the climate changes, species must either move to track favourable conditions, adapt to a new set of conditions, or go extinct. The average species duration is measured in millions of years, so most persist through at least some degree of climate change (Dawson et al. 2011, Moritz and Agudo 2013). For example, any species alive today is descended from a lineage that survived the dramatic cycles of cooling and warming that characterised the Pleistocene era (spanning the period from approximately 2.5 million years ago to 11,000 years ago). Given that life on earth depends on the ability of species to change in response to a changing climate, why are biologists so concerned about species extinction under ongoing climate change? 
Climate change in the Anthropocene may have a more severe extinction cost than past climate oscillations for several reasons. First, the pace of climate change is so rapid that many species may be left behind. The speed of climate change is reflected in changes in species reproduction and distribution which are observable over short time periods in a wide range of ecosystems - examples include earlier grape harvests, range shifts in butterflies, loss of populations of high altitude mammals, extinction of frog species in cloud forests of Central America, decrease in sea-ice dependent algae and krill, and increase in prevalence of pathogens in coral reefs (Hoegh-Guldberg and Bruno 2010, Parmesan 2006, Webb et al. 2011). Second, while some species may be able to shift their geographic range to track the changing climate, species with fragmented or isolated habitats may not be able to move between isolated remnants of suitable habitat. Montane species are a particular cause for concern. Warming temperatures correspond to an upward trend in the distribution of some species, with low altitude species shifting higher up mountains, tracking suitable conditions. But species already on mountain summits cannot go higher, and moving across lowlands to ever higher mountaintops or higher latitudes may be impossible. Third, species already under stress may be limited in their ability to respond to a changing environment. Reduced population size due to habitat modification or other stresses will reduce the ability of a population to respond through adaptation, because selection for new traits that allow persistence under changed conditions will be less effective in small populations (Orr and Unckless 2008). For example, it has been estimated that increase in global temperature after the last ice age led to a 90 per cent reduction in the suitable habitat for woolly mammoths, reducing the population to such a low level that they were particularly vulnerable to human impact (Nogués-Bravo et al. 2008). Many scientists are using ecological and evolutionary modelling to try to predict which species will be able to adapt to a rapidly changing climate and which will not (Moritz and Agudo 2013). Evolutionary biologists are beginning to explore the constraints on 'evolutionary rescue', where genetic change allows a lineage to persist in conditions that would have been lethal to its recent ancestors (Bell 2013). Rapid environmental change may leave insufficient time for potentiating mutations to build increased tolerance in the population (Lindsey et al. 2013).

But within the tolerable range of conditions, success or failure may be determined largely by interactions with other species, whether direct or indirect, so modelling the climatic niche may not be sufficient to predict species response to climate change (Dawson et al. 2011). For example, the movement of species across the landscape may place even greater pressure on locally endemic species, by bringing novel combinations of species into competition with each other (Hoegh-Guldberg and Bruno 2010, Sinervo et al. 2010). Where adaptation to a changing climate might promote directional selection pressure, adaptation 
to other species involves chasing a moving target. This view of evolutionary change in response to the changes in other species is often referred to as the Red Queen model, after the Lewis Carroll character who says that it takes all the running you can do, to keep in the same place' (Carroll 1871). The most obvious expression of the constant evolutionary chase is in the arms races between predators and prey, plants and herbivores, pathogens and hosts.

I began this chapter by pointing out that much of the environment we experience is constructed by living species. Humans are perhaps one of the most obvious examples of the life-built environment, with the activities of our own species leaving few other species wholly unaffected. Evolution has not stopped in these highly modified environments, but continues to drive change in response to this rapidly changing world. For example, bird populations living around highways have been shown to evolve longer wing-lengths, because the shorter-winged individuals are more likely to end up as roadkill and therefore have fewer descendants in subsequent generations (Brown and Bomberger Brown 2013). In many instances, the evolutionary response of other species to the changing environment may be not in people's best interests, such as in the rapid evolution of antibiotic resistance in harmful bacteria. Any significant interaction with other species sets up a strong selection pressure, whether it is the impact of commercial fishing selecting for reduced body size at maturity in fish, the evolution of myxomatosis resistance in rabbits, or the alteration of bird song in noisy urban environments. But understanding evolutionary principles allows these processes to be managed and monitored. For example, strategies employed to prevent crop pests from evolving resistance to the insecticides produced by genetically modified crops have thus far been largely successful (Tabashnik et al. 2013). While evolutionary change is inevitable, understanding evolutionary principles helps us to mitigate biodiversity loss and manage our own interaction with the changing biological world.

\section{Conclusion}

The biological world is in a constant state of flux. The processes of mutation, substitution and divergence occur continuously, though they may vary in rate or pattern over time, space, between different lineages or in different parts of the genome. Studies of the patterns of change in biodiversity over time have supported very different views of the mechanisms of evolutionary change, with some biologists favouring a model of continuous change through the accumulation of many small variations, and others promoting a model of discontinuous evolution, where evolutionary change is concentrated into bursts of significant change followed by long periods of stasis. These issues have been 
debated since Darwin's day, and are reinvented in each age and adapted to new data sources. The explosion of availability of DNA sequences has provided a new platform on which these old arguments are being played out.

Recognising the causes and consequences of evolutionary change is an essential part of appreciating the world around us. But it also complicates our understanding of our interaction with the natural world. How can we preserve biodiversity in an ever changing world? Which species will track the rapid environmental change the world is experiencing, and which will fail to do so? Viewing ourselves as part of a dynamic, ever changing biosphere is critical to human prosperity. Nothing stands still in the biological world.

\section{Acknowledgements}

I am grateful to Camile Moray, David Duchene, Brett Calcott and Xia Hua for their valuable feedback.

\section{References}

Abbott, R, Albach, D, Ansell, S, Arntzen, JW, Baird, SJ, Bierne, N, Boughman, J, Brelsford, A, Buerkle, CA, Buggs, R, Butlin, RK, Dieckmann, U, Eroukhmanoff, F, Grill, A, Cahan, SH, Hermansen, JS, Hewitt, G, Hudson, AG, Jiggins, C, Jones, J, Keller, B, Marczewski, T, Mallet, J, Martinez-Rodriguez, P, Möst, M, Mullen, S, Nichols, R, Nolte, AW, Parisod, C, Pfennig, K, Rice, AM, Ritchie, MG, Seifert, B, Smadja, CM, Stelkens, R, Szymura, JM, Väinölä, R, Wolf, JB and Zinner, D (2013) Hybridization and speciation. Journal of Evolutionary Biology 26(2): 229-46.

Bambach, RK (2006) Phanerozoic biodiversity mass extinctions. Annual Review of Earth and Planetary Sciences 34: 127-55.

Bambach, RK, Knoll, AH and Wang, SC (2004) Origination, extinction, and mass depletions of marine diversity. Paleobiology 30(4): 522-42.

Barraclough, TG and Savolainen, V (2001) Evolutionary rates and species diversity in flowering plants. Evolution 55: 677-83.

Bell, G (2013) Evolutionary rescue and the limits of adaptation. Philosophical Transactions of the Royal Society B: Biological Sciences 368:20120080. 
Bhattacharyya, T, Gregorova, S, Mihola, O, Anger, M, Sebestova, J, Denny, P, Simecek, P, and Forejt, J (2013) Mechanistic basis of infertility of mouse intersubspecific hybrids. Proceedings of the National Academy of Sciences USA 110(6): E468-77.

Bigham, A, Bauchet, M, Pinto, D, Mao, X, Akey, JM, Mei, R, Scherer, SW, Julian, CG, Wilson, MJ, López Herráez, D, Brutsaert, T, Parra, EJ, Moore, LG and Shriver, MD (2010) Identifying signatures of natural selection in Tibetan and Andean populations using dense genome scan data. PLoS Genetics 6(9): el001116.

Bromham, L (2000) Conservation and mutability in molecular evolution. Trends in Ecology and Evolution 15: 355.

Bromham, L (2009) Why do species vary in their rate of molecular evolution? Biology Letters 5: 401-04.

Bromham, L (2011) The small picture approach to the Big Picture: using DNA sequences to investigate the diversification of animal body plans. In K Sterelny and B Calcott (eds) The major transitions in evolution revisited. MIT Press, Cambridge [UK].

Bromham, L and Leys, R (2005) Sociality and rate of molecular evolution. Molecular Biology and Evolution 22(6): 1393-1402.

Bromham, L and Penny, D (2003) The modern molecular clock. Nature Reviews Genetics 4: 216-24.

Brown, CR and Bomberger Brown, M (2013) Where has all the road kill gone? Current Biology 23(6): R233-34.

Carroll, L (1871) Through the looking glass: and what Alice found there. Macmillan, London.

Cornette, JL and Lieberman, BS (2004) Random walks in the history of life. Proceedings of the National Academy of Sciences USA 101(1): 187-91.

Coyne, JA and Charlesworth, B (1996) Mechanisms of punctuated evolution. Science 274: 1748.

Coyne, JA and Charlesworth, B (1997) On punctuated equilibria: a reply to Eldredge and Gould. Science 276(5311): 337-41.

Darwin, C (1859) On the origin of species by means of natural selection: or the preservation of favoured races in the struggle for life. John Murray, London.

Darwin, CR and Wallace, AR (1858) On the tendency of species to form varieties; and on the perpetuation of varieties and species by natural means of selection. Journal of the Proceedings of the Linnean Society of London. Zoology 3: 45-50. 
Dawson, TP, Jackson, ST, House, JI, Prentice, IC and Mace, GM (2011) Beyond predictions: biodiversity conservation in a changing climate. Science 332(6025): 53-8.

Duchene, D and Bromham, L (2013) Rates of molecular evolution and diversification in plants: chloroplast substitution rates correlate with species richness in the Proteaceae. BMC Evolutionary Biology 13: 65.

Elena, SF, Cooper, VS and Lenski, RE (1996) Mechanisms of punctuated evolution. Science 274: 1748-9.

Ezard, THG, Aze, T, Pearson, PN and Purvis, A (2011) Interplay between changing climate and species' ecology drives macroevolutionary dynamics. Science 332(6027): 349-51.

Gellon, G and McGinnis, W (1998) Shaping animal body plans in development and evolution by modulation of Hox expression patterns. BioEssays 20: 116.

Gould, SJ (1980) Is a new and general theory of evolution emerging? Paleobiology 6(1): 119-30.

Gould, SJ (1997) Darwinian fundamentalism. New York Review of Books 44: 34-7.

Hehemann J-H, Correc, GL, Barbeyron, T, Helbert, W, Czjzek, M and Michel, G (2010) Transfer of carbohydrate-active enzymes from marine bacteria to Japanese gut microbiota. Nature 464(7290): 908-12.

Hoegh-Guldberg, O and Bruno, JF (2010) The impact of climate change on the world's marine ecosystems. Science 328(5985): 1523-8.

Hoekstra, HE and Coyne, JA (2007) The locus of evolution: evo devo and the genetics of adaptation. Evolution 61(5): 995-1016.

Hua, X and Wiens, JJ (2013) How does climate influence speciation? American Naturalist 182(1):1-12.

Jablonski, D and Chaloner, WG (1994) Extinctions in the fossil record [and Discussion]. Philosophical Transactions of the Royal Society of London. Series B: Biological Sciences 344(1307): 11-17.

Lampert, KP, Fricke, H, , Hissmann, K, Schauer, J, Blassmann, K, Ngatunga, BP and Schartl, M (2012) Population divergence in East African coelacanths. Current Biology 22(11): R439-40.

Lanfear, R, Ho, SYW, Love, D and Bromham, L (2010) Mutation rate influences diversification rate in birds. Proceedings of the National Academy of Sciences USA 107(47): 20423-8. 
Change!

Lanfear, R, Ho, SYW, Davies, TJ, Moles, AT, Aarssen, L, Swenson, NG, Warman, L, Zanne, AE and Allen, AP (2013) Taller plants have lower rates of molecular evolution: the rate of mitosis hypothesis. Nature Communications 4: 1879.

Li, WH, Yi, S and Makova, KD (2002) Male-driven evolution. Current Opinion in Genetics \& Development 12: 650-6.

Lindsey, HA, Gallie, J, Taylor, S and Kerr, B (2013) Evolutionary rescue from extinction is contingent on a lower rate of environmental change. Nature 494: 463-6.

Lloyd, GT, Pearson, PN, Young, JR and Smith, AB (2012) Sampling bias and the fossil record of planktonic foraminifera on land and in the deep sea. Paleobiology 38(4): 569-84.

Mallet, J (2010) Why was Darwin's view of species rejected by twentieth century biologists? Biology and Philosophy 25(4): 497-527.

Marshall, CR, Orr, HA and Patel, NH (1999) Morphological innovation and developmental genetics. Proceedings of the National Academy of Sciences 96: 9995-6.

Mayhew, PJ, Bell, MA, Benton, TG and McGowan, AJ (2012) Biodiversity tracks temperature over time. Proceedings of the National Academy of Sciences USA 109(38): 15141-5.

Maynard Smith, J (1958) The theory of evolution. Penguin Books, London.

Maynard Smith, J (1981) Did Darwin get it right? London Review of Books 3(11): 10-11.

Maynard Smith, J (1983) The genetics of stasis and punctuation. Annual Review of Genetics 17(1):11-25.

Mayor, A (2000) The first fossil hunters: paleontology in Greek and Roman times. Princeton University Press, Princeton NJ.

McKinnon, JS and Taylor, EB (2012) Biodiversity: species choked and blended. Nature 482(7385): 313-14.

Mi, S, Lee, X, Li, X, Veldman, GM, Finnerty, H, Racie, L, LaVallie, E, Tang, XY, Edouard, P, Howes, S, Keith, JC Jr and McCoy, JM (2000) Syncytin is a captive retroviral envelope protein involved in human placental morphogenesis. Nature 403: 785-9. 
Moritz, C and Agudo, R (2013) The future of species under climate change: resilience or decline? Science 341(6145): 504-08.

Mower, JP, Stefanović, S, Young, GJ and Palmer, JD (2004) Plant genetics: gene transfer from parasitic to host plants. Nature 432(7014): 165-66.

Nachman, MW and Crowell, SL (2000) Estimate of the mutation rate per nucleotide in humans. Genetics 156(1): 297-304.

Nogués-Bravo, D, Rodriguez, J, Hortal, J, Batra, P and Araújo, MB (2008) Climate change, humans, and the extinction of the woolly mammoth. PLoS Biology 6(4): e79.

Normark, BH and Normark, S (2002) Evolution and spread of antibiotic resistance. Journal of Internal Medicine 252(2): 91-106.

Nosil, P and Schluter, D (2011) The genes underlying the process of speciation. Trends in Ecology and Evolution 26(4): 160-7.

Ochman, H, Lawrence, JG and Groisman, EA (2000) Lateral gene transfer and the nature of bacterial innovation. Nature 405(6784): 299-304.

Orr, HA and Unckless RL (2008) Population extinction and the genetics of adaptation. American Naturalist 172(2): 160-9.

Orr, HA, Masly, JP and Presgraves, DC (2004) Speciation genes. Current Opinion in Genetics \& Development 14(6): 675-9.

Pagel, M, Venditti, C and Meade, A (2006) Large punctuational contribution of speciation to evolutionary divergence at the molecular level. Science 314(5796): 119-21.

Parmesan, C (2006) Ecological and evolutionary responses to recent climate change. Annual Review of Ecology, Evolution, and Systematics 37: 637-69.

Patel, PH and Loeb, LA (2000) DNA polymerase active site is highly mutable: evolutionary consequences. Proceedings of the National Academy of Sciences 97: 5095-5100.

Peters, SE and Foote, M(2001) Biodiversity in the Phanerozoic: a reinterpretation. Paleobiology 27(4): 583-601.

Rieseberg, LH and Willis, JH (2007) Plant speciation. Science 317(5840): 910-14.

Rohde, RA and Muller, RA (2005) Cycles in fossil diversity. Nature 434(7030): 208-10. 
Rudwick, MJ (1976) The meaning of fossils: episodes in the history of palaeontology. University of Chicago Press.

Sarich, VM and Wilson, AC (1967) Immunological time scale for hominid evolution. Science 158(805): 1200.

Sepkoski, D (2012) Rereading the fossil record: the growth of paleobiology as an evolutionary discipline. University of Chicago Press.

Sheehan, PM (1977) Species diversity in the Phanerozoic: a reflection of labor by systematicists? Paleobiology 3: 325-9.

Sinervo, B, Mendez-de-la-Cruz, F, Miles DB, Heulin, B, Bastiaans, E, VillagránSanta Cruz, M, Lara-Resendiz, R, Martínez-Méndez, N, Calderón-Espinosa, ML, Meza-Lázaro, RN, Gadsden, H, Avila, LJ, Morando, M, De la Riva, IJ, Sepulveda, PV, Rocha, CFD, Ibargüengoytía, N, Puntriano, CA, Massot, M, Lepetz, V, Oksanen, TA, Chapple, DG, Bauer, AM, Branch, WR, Clobert, J and Sites, JW Jnr (2010) Erosion of lizard diversity by climate change and altered thermal niches. Science 328(5980): 894-9.

Smith, AB (2001) Large-scale heterogeneity of the fossil record: implications for Phanerozoic biodiversity studies. Philosophical Transactions of the Royal Society B 356: 351-67.

Soltis, PS and Soltis, DE (2009) The role of hybridization in plant speciation. Annual Review of Plant Biology 60(1): 561-88.

Stanley, SM (1979) Macroevolution: pattern and process. WH Freeman and Company, San Francisco.

Tabashnik, BE, Brévault, $\mathrm{T}$ and Carrière, Y (2013) Insect resistance to Bt crops: lessons from the first billion acres. Nature Biotechnology 31(6): 510-21.

Varki, A and Altheide, TK (2005) Comparing the human and chimpanzee genomes: searching for needles in a haystack. Genome Research 15(12): 1746-58.

Webb, LB, Whetton, PH and Barlow, EWR (2011) Observed trends in winegrape maturity in Australia. Global Change Biology 17(8): 2707-19.

Welch, JJ (2004) Accumulating Dobzhansky-Muller incompatibilities: reconciling theory and data. Evolution 58(6): 1145-56.

Wolf, JBW, Lindell, J and Backstrom, N (2010) Speciation genetics: current status and evolving approaches. Philosophical Transactions of the Royal Society $B$ 365(1547):1717-33. 
This text is taken from Change! Combining Analytic Approaches with Street Wisdom, edited by Gabriele Bammer, published 2015 by ANU Press, The Australian National University, Canberra, Australia. 